\title{
DIGITAL SUPPORT FOR THE PRE-STUDENT PHASE IS SUCCESSFUL
}

\author{
Pia Drews and Alke Martens \\ University of Rostock, Institute of Computer Science \\ Albert-Einstein-Str. 22, 18059 Rostock, Germany
}

\begin{abstract}
Juniorstudy is a concept of the University of Rostock, which can be used by school students before starting their time at the University. Thus, it is an instrument of supporting the choice of study direction. Moreover, we have been able to show in our last cohort, that using Juniorstudy courses also helps to significantly enhance the knowledge required to start the university study, thus our courses become an important tool for bridging the gap between school and University. In this paper we will show the results of our study which shows that our approach improves the students' knowledge and thus facilitates being successful in testes and exams in the basic courses in the first term.
\end{abstract}

\section{KEYWORDS}

Online Study, Digital Study, Junior Study Program

\section{INTRODUCTION}

Orientation programs for school students can be found at Universities since the 1970s (e.g. Solzbacher, 2018; Deutsche Telekom Stiftung, 2018). Initially, these programs stem from the support of highly gifted school students, and historically were launched as a side effect of allowing early performers to join University programs. Over the years, these kind of programs have been established at quite a lot of Universities worldwide (e.g. Falzer, 1987; Solzbacher, 2018; Gröber et al., 2018; Drews, Martens, 2019).

In Germany, such approaches are often called Juniorstudyprograms - thus, we have called our project the "Juniorstudium of the University of Rostock". In the following, when we say "Juniorstudium" we refer to our project. The students (who are still at school) will be called Juniorstudents, to distinguish them from the enrolled regular students. The project was started with an external funding in 2008. During this time, we have fine-tuned our approach and resulting in a project, which is outstanding in Germany. It is not developed for highly gifted students only, but is open for everyone who is a German school student.

As far as we know, there have been few studies on the learning success of Juniorstudents. Therefore, this study should show the first results of the success of the Juniorstudium. We focus on school students starting their $10^{\text {th }}$ grade (the German system has 12 grades ending with the baccalaureate, phase of $10^{\text {th }}$ to $12^{\text {th }}$ grade is called Sekundarstufe II - Sek II in Germany). Our Juniorstudium consists of a program of three columns (Waßmann et al. 2015; Waßmann 2018). The first column consists of recording of first and second term lectures. These are life recordings, refined and prepared for the Juniorstudium afterward. Currently we have around 20 different lecture courses from various fields, including Medicine, STEM fields (STEM = Science, Technology, Engineering, Mathematics), but also topics like Psychology or Pedagogics. As side effect, in this column, we offer the Juniorstudents a variety of potential topics for their study decision, which is an aspect of our University's orientation program. The second column consists of homework, tests and interaction elements. Depending on the course the Juniorstudents have chosen, they have to solve homework tasks, they can participate on tests and in some cases can get credit points, which are re-usable after enrollment at University of Rostock. 
Regarding the third column, we learned over the years that our best approach is a close connection between the Juniorstudents and student tutors. For us it is of major importance, that the Juniorstudents are not only accompanied during their participation on a digital lecture in form of homework support, but that they are accompanied by senior students, which can answer questions regarding the content of the topic, but also questions regarding student life, emotional feelings of being a student, and organizational aspects. Feedback from our Juniorstudents is that this combination is well received. The study materials, i.e. the digital lectures, additional digital material, tests and homework are organized on the platform Stud.IP (https://www.studip.juniorstudium.uni-rostock.de) by the student tutor, who is responsible for a group of 3 to 60 Juniorstudents. Additional functions like chat and forum can be used. In most cases, tutors and Juniorstudents are in contact via email.

We have participants from all over Germany, and we have several schools, which have made a close cooperation with our project and integrated this as a permanent offer in their Sek II program. Currently we have over 300 students (summer term 2020). Quite naturally, we have been a strong support for our Juniorstudents during the Corona Crisis.

Based on this background, a while ago we started with different research projects, one of which steers the research shown in this paper. In the following, we describe the basic idea, the study design and the results.

\section{DESCRIPTION OF THE STUDY}

We have an annual evaluation regarding the quality of our program. However, some terms ago, we started to take a closer look at our Juniorstudents. We wanted to find out which "type" of student starts in our program, as we are not focusing on highly gifted students, and we wanted to investigate, if different specified learner types exist in our courses (Kolb, 1981; Drews, Martens, 2019). For example, in one part of the study we asked for motivational aspects to take up a part-time study during school time, whether it was their own idea or the idea of teachers and/or parents, etc. Hidden behind this is the idea, that we have high performers, which don't fall into the psychological category of highly gifted (e.g. Stanley 1996; Möller, 2006), but which are nonetheless bright and eager to learn - as long as the material is interesting enough (McLeod, 2019). In the research shown in (Drews, Martens, 2019), we work together with psychologists and instructional designers. We have focused in that study, same as in the study described in this paper, on our students in the medicine tracks, as this is our largest group with over 200 participants annually.

The study, sketched in this paper, is based on the following background. Currently students in the Sek II in German schools have to choose few courses for intense study, and others for basic study. Often, courses overlap - thus, due to organizational aspects, in quite a lot of schools it is not possible to select for example all basic courses in all nature sciences to prepare for University. As a result, we find a lot of students entering the University without having Sek II courses in Chemistry or Biology or Physics (neither basic nor intense). The Universities in Germany reacted to this with establishing "Crash-Courses" in Chemistry, Biology and Physics for students in human medicine. With courses of actions like these, Universities try to give all students equal opportunities. However, in real life, these crash courses are really challenging, and come in a time where everything is demanding for the new students.

For the Juniorstudium it was an obvious idea to put these courses in the phase where the students are still at school and investigate, whether this might be more fruitful. Thus, we try to close the gap between school and University in an early stage and offer better start chances at the University. To the best of our knowledge, the extent to which young German students benefit from early studies has never been investigated. The aim of this study is to examine the learning success of Juniorstudents by the example "Chemistry for Medicine", also in comparison to regular students at the beginning of their studies.

The course "Chemistry for Medicine" in medical studies consists of 21 lectures, each of which takes 105 minutes working time. Additionally, the course offers 7 online practical training unit videos each of which takes 3 hours of time. This is too much for a full-time school student and part-time Juniorstudent, thus we have split the course in two halves and extended the time for working through the digital material over two terms which 14 videos and 4 practical exercises in each term. Moreover, the tutor offers a presence seminar at University of Rostock to practice exercises in preparation of the final exam - this takes place each term.

At the summer term 2019, we started with our chemistry course, which is only focused on anorganic chemistry, and repeated the course again starting in winter term 2019/2020. From the 210 enrolled 
Juniorstudents in the summer term 2019, an amount of 26 Juniorstudents decided to choose the "Chemistry for Medicine" course. In winter term 2019/2020, we had 300 Juniorstudents enrolled, and 51 of those decided for "Chemistry for Medicine". We think that this large amount of Juniorstudents has two backgrounds: a) based on a survey at the start of the term we know, that quite a lot students learned from friends and teachers about the existence of the course, and b) school students are eager to take the opportunity, when they learn that they have the chance to participate on the real University exam (together with the enrolled students) after they have successfully passed the two tests required to finish the Juniorstudy Chemistry module.

\section{METHODS}

The module starts with a presence based pre-test (duration: 90 minutes), so that we had a chance to find out the knowledge gained from school. After seeing all the required material and tests, as described above, at the end of the term, the course is finished with a presence based post-test (duration: 90 minutes).

Both tests consist of a set of 35 questions, which have to be answered. Of these, this article only looks at 6 questions on mathematical principles and 6 questions on chemistry mathematics.

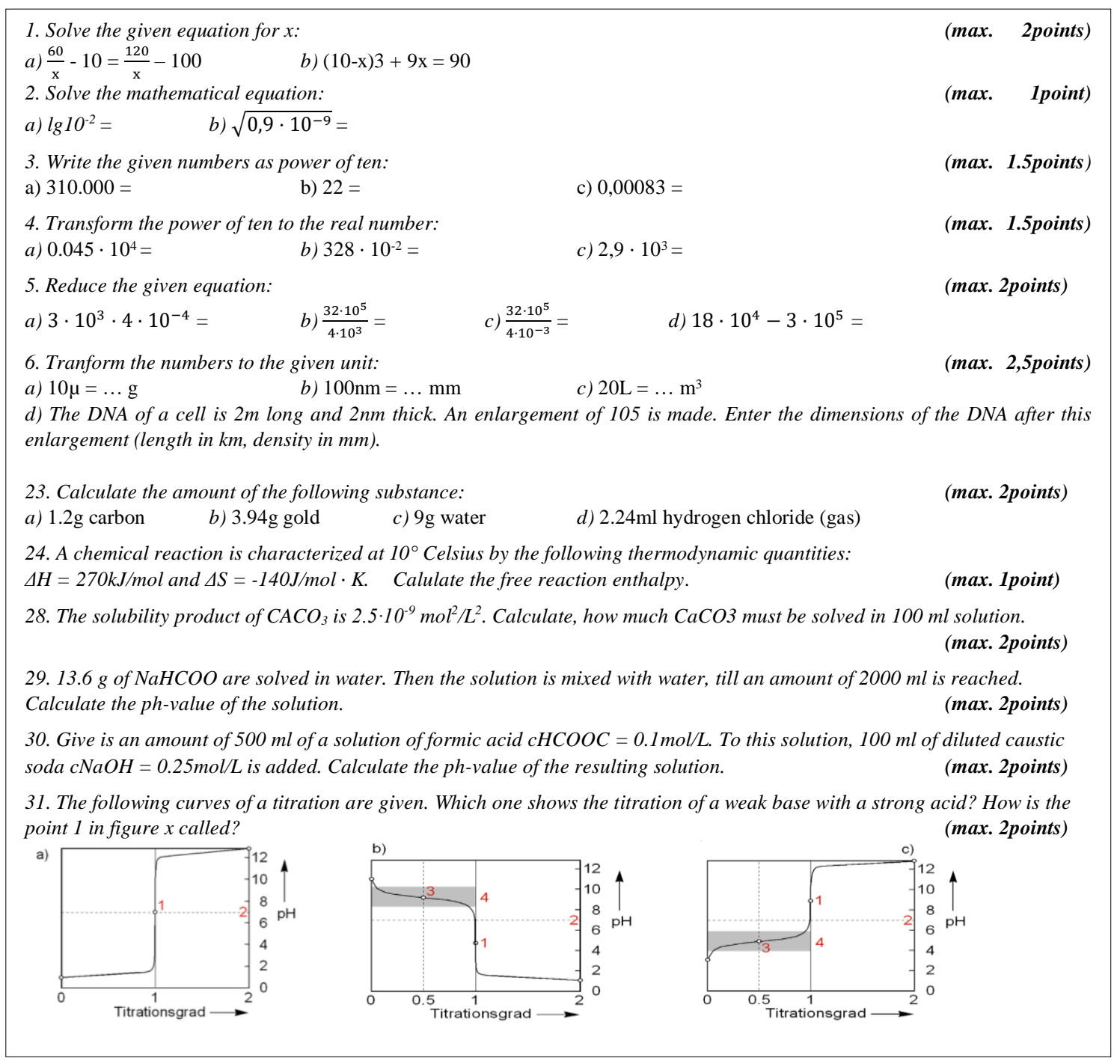

Figure 1. Questions 1 to 6 - mathematical basics. Question 23, 24, 29 to 31: chemistry mathematics 
In the mathematical part of the test, no additional materials and no pocket calculators were allowed. For the other 29 questions, small (not programmable) pocket calculators, the table of periodic elements and small mathematical formularies are allowed to be used. All the questions are mapped to a competence matrix, containing information like "I am able to calculate the ph-value of anorganic acids." This competence matrix is needed, as different questions relate to different competences. The tests and the matrices have been developed by the responsible lecturer from the Chemistry Department at the University of Rostock.

The statistic of the collected data were evaluated in SPSS (Version 27, IBM Corp., 2020). Since there was no normal distribution, the Wilcoxon-Mann-Whitney-Test was used to compare the Juniorstudents pre- and post-tests and the Mann-Whitney-U-Test was used for the statistical evaluation the post-test of the Juniorstudents compared to the test of first term students.

\section{EVALUATING THE RESULTS}

In summer term 2019 and winter term 2019/20, we had an amount of 23 out of 77 Juniorstudents in the "Chemistry for Medicine" lecture, who participated in the study. Most of the participants are school students of the Sek II $(n=16)$, seven Juniorstudents are currently in the waiting phase for a place in medicine at any University in Germany. The average age of the Juniorstudents is 17,9 years. In the beginning of the term, 6 out of 23 of the Juniorstudents would have passed the test (with an overall score of 50\% required). The mean score was $41 \%$ of the overall score. At the end of the term, the Juniorstudents achieved the mean total score of $66 \%$. 19 of 23 Juniorstudents passed the exam.

As a control group, we used students of the first term enrolled in medicine at the University of Rostock, with $\mathrm{n}=22$. At the date of investigation, these 22 participants are between 17 and 28 years old, with an average age of 20,1 years. Four of the students are over 20 years old - this is due to the fact that waiting on a place to study medicine in Germany can take up to seven years. When those students enter the first term, they have often finished another medical qualification (e.g. care giver). However, as they are exemplary for those classical first term students, which did not get a place at the University directly after finishing school, we have integrated them in our study as well.

From first term medicine students participating on this study at their first week of study, we had three persons with a baccalaureate finished in 2017, five persons finished in 2018 and nine persons in 2019. From two persons, the information is missing, some have older baccalaureates as they had waited for a place for study medicine. Generally speaking, regarding the control group, the baccalaureate is not that far away to assume a complete loss of chemistry knowledge.

We also checked, whom of the Juniorstudy group and of the control group has or had chemistry at Sek II, or even chemistry as selected course in their baccalaureate. Regarding the control group, only two persons have had chemistry as part of their baccalaureate exams (i.e. intensive course), 13 persons have had chemistry in their Sek II. Seven of 23 Juniorstudents already passed their baccalaureate, seven Juniorstudents are in $11^{\text {th }}$ grade, eight Juniorstudents are in their final school year.

Regarding our comparative study, we have been able to observe the following. We have made the tests with both groups, i.e. the Juniorstudy group and the new enrolled students of medicine. The Juniorstudents were questioned in summer term 2019 and winter term 2019/2020 both at the beginning and end of the term. The students were questioned in winter term 2019/2020 in the beginning of their studies.

In the post-test, the Juniorstudents succeeded in 24 of 35 tasks and reached $66 \%$ of the total. Taking the $50 \%$ benchmark for passing the exam, 19 of the 23 Juniorstudents would have passed the real exam. This is incredible, compared with the 1 (one!) person passing in the enrolled student group, mentioned above (there, one person out of $n=22$ has passed the exam).

For our purpose, we wanted to look deeper into the details of this. Thus, we have analyzed the difference between pre- and post-test results based on the question types and the competence matrix. As mentioned in the above section, we had the pre- and post-test content separated in three parts: a) fundaments of mathematical calculation, b) anorganic chemistry, and c) chemical calculation (which again is mainly mathematics, but closely related to chemistry). The most significant differences in the results have been the differences between the pre- and the post-test related to the categories a) and c), i.e. both topics which are related to mathematics. 
This can be seen in detail in the following figures. In figure 2 and table 1 the values for the Juniorstudy group can be seen. In figure 3 and table 2, the results of the enrolled first term students who never attended the Juniorstudium are compared with the Juniorstudents post-test results.
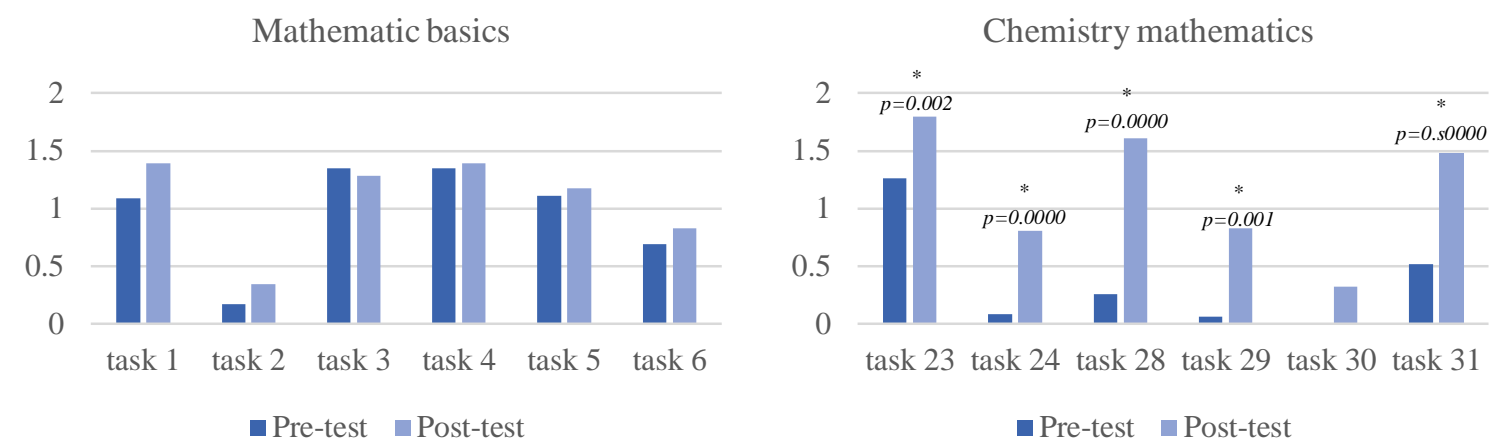

Figure 2. On the left side, the results the Juniorstudents reached in the basic mathematics is shown, on the right side are the results on chemistry mathematics. The darker columns show the results in the pre-test. The lighter columns show the results in the post-test. The p-values are rounded to the fourth position after decimal point

The related statistical results are shown in table 1.

Table 1. Results of Juniorstudents in pre- and posttest. Upper half: mean values and standard deviation of the tasks about basic mathematics, bottom half: mean values and standard deviation in chemistry mathematics

\begin{tabular}{|l|c|c|c|c|c|c|c|c|c|c|c|c|}
\cline { 2 - 14 } \multicolumn{1}{c|}{} & \multicolumn{5}{c|}{ Pre-test Juniorstudents } & \multicolumn{5}{c|}{ Post-test Juniorstudents } \\
\hline task & 1 & 2 & 3 & 4 & 5 & 6 & 1 & 2 & 3 & 4 & 5 & 6 \\
\hline average & 1.09 & 0.17 & 1.35 & 1.35 & 1.11 & 0.70 & 1.39 & 0.35 & 1.28 & 1.39 & 1.17 & 0.83 \\
\hline $\begin{array}{l}\text { standard } \\
\text { deviation }\end{array}$ & 0.73 & 0.32 & 0.32 & 0.44 & 0.71 & 0.89 & 0.78 & 0.35 & 0.42 & 0.34 & 0.75 & 0.72 \\
\hline \hline task & 23 & 24 & 28 & 29 & 30 & 31 & 23 & 24 & 28 & 29 & 30 & 31 \\
\hline average & 1.26 & 0.09 & 0.26 & 0.07 & 0.00 & 0.52 & 1.79 & 0.80 & 1.61 & 0.83 & 0.33 & 1.47 \\
\hline $\begin{array}{l}\text { standard } \\
\text { deviation }\end{array}$ & 0.58 & 0.29 & 0.69 & 0.23 & 0.00 & 0.59 & 0.39 & 0.60 & 0.72 & 0.82 & 0.63 & 0.73 \\
\hline
\end{tabular}

It can be seen, that the Juniorstudents did have some problems in basic mathematics that persisted over the term (left side of figure 2).

Surprisingly, task 1, 2 and 6 were the most complicated for the Juniorstudents. At the beginning of the term, the Juniorstudents were told that basic mathematics is part of the final exam/post-test and that they are not taught in Juniorstudium lectures because they are assumed to have this knowledge from school mathematics education. So the problem that basic mathematic abilities are missing seems to be a problem in school teaching - we can only guess, whether this is simply too long ago at that point or whether they are too focused on pocket calculators. However, we had the impression, that it is also a lack of personal commitment to catch up on the basics as recommended, which should be an important general quality of a student!

Looking at the tasks about chemistry mathematics (for which a calculator could be used), we have achieved following results. It would have been expected that Juniorstudents, which have not yet finished their baccalaureate, perform similar but not better than students which have finished the baccalaureate (thus, assumingly had more knowledge). Surprisingly, we have been able to show, that the Juniorstudents perform significantly better in all the aspects of anorganic chemistry ( 21 of the 29 tasks have been answered significantly better!). 

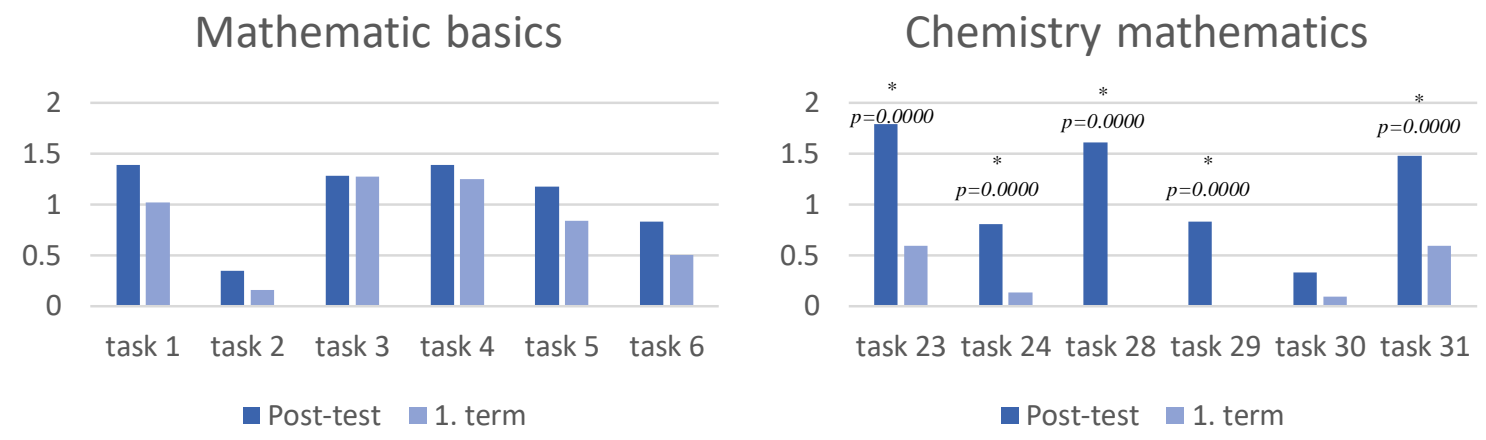

Figure 3. On the left side, the results of the Juniorstudents compared with the students reached in the basic mathematics is shown, on the right side are the results on chemistry mathematics. The darker columns show the results in the post-test with the Juniorstudents. The lighter columns show the results in the exam at the beginning of the 1st term medicine

The related statistical results are shown in table 2 .

Table 2. Results of Juniorstudents posttest und students of their 1st term. Upper half: mean values and standard deviation of the tasks about basic mathematics, bottom half: mean values and standard deviation in chemistry mathematics

\begin{tabular}{|l|c|c|c|c|c|c|c|c|c|c|c|c|}
\cline { 2 - 14 } \multicolumn{1}{c|}{} & \multicolumn{5}{c|}{ Post-Test Juniorstudents } & \multicolumn{6}{c|}{ Test of students } \\
\hline task & 1 & 2 & 3 & 4 & 5 & 6 & 1 & 2 & 3 & 4 & 5 & 6 \\
\hline average & 1.39 & 0.35 & 1.28 & 1.39 & 1.17 & 0.83 & 1.02 & 0.16 & 1.27 & 1.25 & 0.84 & 0.50 \\
\hline $\begin{array}{l}\text { standard } \\
\text { deviation }\end{array}$ & 0.78 & 0.35 & 0.42 & 0.34 & 0.75 & 0.72 & 0.70 & 0.24 & 0.48 & 0.48 & 0.64 & 0.53 \\
\hline \hline task & 23 & 24 & 28 & 29 & 30 & 31 & 23 & 24 & 28 & 29 & 30 & 31 \\
\hline average & 1.79 & 0.80 & 1.61 & 0.83 & 0.33 & 1.47 & 0.59 & 0.14 & 0.00 & 0.00 & 0.09 & 0.59 \\
\hline $\begin{array}{l}\text { standard } \\
\text { deviation }\end{array}$ & 0.39 & 0.60 & 0.72 & 0.82 & 0.63 & 0.73 & 0.72 & 0.32 & 0.00 & 0.00 & 0.20 & 0.59 \\
\hline
\end{tabular}

Juniorstudents performed better in both parts of the test: in mathematics, they are slightly better than the students at the beginning of their $1^{\text {st }}$ term. Even more impressive are the results in the chemistry mathematics: here, the Juniorstudents performed significantly better than the $1^{\text {st }}$ term students! Especially task number 28 has not been solved by the $1^{\text {st }}$ term students, but by almost all Juniorstudents.

We observed the further results of the Juniorstudents. Out of 23 study participants, 20 Juniorstudents took part in the $2^{\text {nd }}$ term. Of these, 13 were admitted to the final exam. In the end, 11 out of 23 Juniorstudents graduated successfully - the best result was an $97 \%$. On average $80 \%$ were reached. According to the lecturer Dr. Gisela, some Juniorstudents achieve significantly better results than regular students who have completed the "Chemistry for Medicine" during their first term.

\section{CONCLUSION AND OUTLOOK}

In our study, we have compared the learning success of Juniorstudents with the state of knowledge that our first term students have. The result, as mentioned in the section above, clearly shows that in contrast to our expectations, Juniorstudents had an impressing learning success during the term and especially compared to students of the first term. This came unexpected, as the enrolled students are highly motivated and have finished their school time, hence our assumption has been that they would have an advantage. Thus, summing up the result of this investigation is that the course "Chemistry for Medicine", which is identical with the module offered at the first term, is a very good offer for school students. 
What makes the Juniorstudium at the University of Rostock unique is the fact that everybody who is interested and who is still at school is allowed to participate on the courses - independent of any "highly gifted" attest. As the courses are digital, and the complete program is "digital with person-to-person support", we have participants from all over Germany. Courses like the "Chemistry for Medicine" offered in our Juniorstudium, are a significant element for preparing for University, especially as we have been able to show in this study that Juniorstudents significantly perform better than first term students, resulting in deeper knowledge in Chemistry after starting their University life. Thus they have lesser problems being successful in their study time. At least, it lies at hand that they have less problems in the above mentioned "Crash course" which is part of the first term.

Even if our first study offers surprising results, we are still working on broadening the evaluation. We are planning to repeat the study in the next years, plus we establish a test for the students, which will help us to learn whether they have developed a deeper understanding of chemistry and thus have lesser problems in chemistry during their study time.

We don't want to be so bold to say that as a result "digital" is better than "life" - which is really not our impression. And which does not reflect what the students tell us - they really love life lectures at the campus, especially in the first terms, and, given the choice, would have never swapped life courses against digital ones.

So summing up, our first study reveals that in the case of medicine study programs, the integration of Juniorstudyprograms in school is a valuable tool in two ways:

a) It was out of question in the past time, that Juniorstudy program are very valuable for finding the fitting study direction while still visiting school. Quite a lot of school students decide for a study direction which is well known to them, either from their family or from their own experience. This has been revealed for medicine in (Drews, Martens, 2019). Often, these students find out after their first two terms that they have made the wrong decision and swap study directions. Whatever the reasons are, these are counted as drop outs for each study direction.

b) Our first study shows, that - if temporal resources allow it - Juniorstudy programs are a valuable additive for students at the Sek II in Germany.

Interesting for us - as a side track - has been the question, whether the chemistry module is simply too difficult for the students. This is also a usual assumption for student drop out in the first terms (e.g. Waßmann et al., 2015; Egetenmeier, 2018). We started with this as a pre-assumption from the medicine lecturer staff. However, our chemistry lecturer had the impression, that chemistry simply overburdens the University starters, and as they want to become physicians, and have problems to accept that basic chemistry is a necessary part of the study program. We can observe a similar situation in computer science, where most students have problems with the mathematics required (which has been shown in another study running for several years now in the Computer Science Department - not published, yet, but also observed in (Bildungsministerium, 2017)). The result of the detailed analysis and comparison between pre- and post-test related to the question categories (i.e. mathematic, anorganic chemistry, and chemical mathematics) revealed that the main problem seems to be the mathematics! This leads us to think about a finer grained approach for the Juniorstudents and the enrolled full-time students, who seemingly have both the same problem - and it is not acquiring the knowledge related to anorganic chemistry. We have asked several students and Juniorstudents about this in our competence matrix, and learned, that they were themselves completely unaware of their lack of mathematical knowledge.

As a next step, it would also be very interesting to support this insight with additional material, e.g. Juniorstudents and students from other topics, which require basic mathematical knowledge - which are mainly all topics related to the field of STEM. Also, it might be fruitful to investigate how the school curriculum is related to the expected University curriculum. We are currently working in this direction together with instructional designers (in German: Didaktiker) from the field of Mathematics and Computer Science.

\section{ACKNOWLEDGEMENT}

We want to thank Dr. Gisela Boeck for her support and for being a brilliant lecturer of the course, and the students working in her lab and acted as tutors in our Juniorstudy. We thank the University of Rostock, which is financing this project. 


\section{REFERENCES}

Bundesministerium für Bildung und Forschung. Pressemeldung, https://www.bmbf.de/de/studienabbrecher-beginnenhaeufig-eine-berufsausbildung-4283.html (2017) last accessed 2019/06/26.

Deutsche Telekom Stiftung, Solzbacher, C.: Frühstudium - Schüler an die Universität. Osnabrück (2008).

Deutsche Telekom Stiftung: Frühstudium Telekom Stiftung, Bonn (2011).

Drews, Pia, Martens, Alke: Juniorstudium - Study Digital while Going to School. In: Herzog, M.A., Kubincova, Z., Han, P., Temperini, M. (Eds): Advances in Web-Based Learning ICWL 2019, pp. 313 (2019).

Egetenmeier, A. Analyse des fachlichen Studienabbruchs an einer Hochschule. eleed, Iss. 12. (urn:nbn:de:0009-5-46635) (2018).

Fatzer, G.: Ganzheitliches Lernen. Humanistische Pädagogik und Pädagogik und Organisationsentwicklung, Junfermann-Verlag, Paderborn (1987).

Gröber, S., Müller, T., Kuhn, J.: The early entrance physics program FiPS. Physik und Didaktik in Schule und Hochschule, $1-12(2018)$

Kolb, D. A.: Learning styles and disciplinary differences. In: The modern American college, 232-255. Jossey-Bass, San Francisco (1981).

McLeod, S. A.: Kolb - learning styles, https://www.simplypsychology.org/learning-kolb.html last accessed 2019/08/11.

Möller, H.: Die Lernstilanalyse nach Kolb und ihre Konsequenzen für die Hochschul- und Schuldidaktik und die berufliche Aus- und Weiterbildung. In: 1. Innsbrucker Bildungstage, pp. 88-94. Univ. Press Insbruck (2006).

Stanley, Julian C.: In the Beginning: The Study of Mathematically Precocious Youth. Intellectual Talent: Psychometric and Social Issues, 225-235 (1996).

Waßmann, I.; Dharma - Dynamic, Heuristic \& Adaptive Peer Recommendation in Social Learning Environments. In: International Technology, Education and Development (INTED) Conference Proceedings. pp. 3515-3525 (2018).

Waßmann, I., Müller, M., Tavangarian, D.: Adaptive Lehrvideos. In: DeLFI 2015, 13. E-Learning Fachtagung Informatik, pp. 131-144. GI Edition, Bonn (2015) 